\title{
Universities as Living Labs for Climate Praxis
}

\author{
Zoe P. Robinson, Philip Catney, Philippa Calver, \\ and Adam Peacock
}

Highlights University living lab success relies on careful navigation of complex relationships between different actors. Maximising change through living labs requires educational objectives and learning processes embedded in governance.

Keywords Climate change - Living labs - Universities - Campuses · Climate praxis

Z. P. Robinson $(\bowtie) \cdot$ A. Peacock

Institute for Sustainable Futures/School of Geography, Geology and the Environment, Keele University, Keele, UK

e-mail: z.p.robinson@keele.ac.uk

P. Catney

School of Social, Political and Global Studies, Keele University, Keele, UK

P. Calver

Tyndall Centre for Climate Change Research, University of Manchester, Manchester, UK

(C) The Author(s) 2022

C. Howarth et al. (eds.), Addressing the Climate Crisis, https://doi.org/10.1007/978-3-030-79739-3_12 


\section{INTRODUCTION}

Climate imperatives have led to an increased interest in the use of 'living labs' as places of experimentation and innovation for climate-related solutions. The term living lab in the context of this paper is used to describe the combination of a place (e.g. a university or city) and a research and built environment management approach where innovations are trialled in the 'real world' for the purpose of both making sustainable improvements and generating learning about the effectiveness of the solution and implementation process. Living Labs can occur at different scales, but are typically viewed as geographically bounded and involving intentional interventions and feedback loops to facilitate adaptive learning, and experimental forms of collaborative governance between diverse stakeholders (Evans \& Karvonen, 2014; Evans et al., 2015 ). Alongside the development of urban living labs, developed in partnership between government and public and private property owners (see Evans \& Karvonen, 2014), university campuses provide additional venues for the development of living labs as places of climate praxis. Both settings share some characteristics; however, each has their own opportunities and challenges.

Universities can impact climate praxis in many ways, one example is that, as sizable organisations, they have significant energy demands. An increasing imperative to reduce carbon emissions from their estates is reflected in the numerous university declarations of a climate emergency and ambitious net-zero targets. Universities have the potential to catalyse wider-scale changes in climate praxis through education, research and business engagement activities. Additionally, with a growing emphasis on partnerships with industry and government, universities are increasingly playing an important part in their wider regions as 'anchor institutions', providing leadership and support on issues such as economic development, health and environmental matters (Birch et al., 2013). These factors demonstrate that university campuses are 'privileged space[s] of innovation' (Evans \& Karvonen, 2014, p. 415), offering the potential to trial new governance approaches and technologies for climate change mitigation in ways that may be difficult to undertake in other public settings.

It is critical to recognise that whilst all universities can contribute to climate praxis, not all are equally placed to perform as living labs. Factors that contribute to universities as propitious places for exploring climate 
solutions include independent management of their utility networks, control over a multi-use built environment (including retail, catering, leisure, conferencing, offices, residential and laboratory facilities) and a significant and diverse community of staff and students who may live and work within the university campus ecosystem. Often this campus ecosystem represents the scale and complexity of a small town, in turn securing their potential as living labs (Colding \& Barthel, 2017).

Even where this combination of useful characteristics is present, significant challenges remain. For example, the complexity of the university ecosystem, one of the qualities that make university living labs so attractive in the first place, needs to be considered explicitly as part of project design and implementation. To this end, this chapter draws on reflections from two university-based, campus-scale sustainable energy-transition 'living lab' projects to explore two key areas of challenges and opportunities that require consideration if we are to maximise the potential of universities as places of climate praxis.

After outlining the projects and setting for the living lab, our first reflection explores the experiences of those in the living lab and how these may be mediated by their relationships with the university and the complexity of their interlinked private and public spheres. In addition, we highlight the need for project implementers to be sensitive to the position and views of the living lab 'users'. The second reflection explores how to harness university-based living lab projects to address specific educational opportunities within a university living lab, and enhance climate change and energy literacy, helping to prepare society for sustainable transitions.

\section{The Living Lab Projects}

The reflections of the two energy-transition projects based at one university are drawn from the different positionalities and roles of the authors in relation to the projects. These include formal academic representation in project governance, data collection, membership of the staff, student, and resident community, and roles pertaining to sustainability governance in the university. The reflections are also influenced by interview data collected from research carried out in relation to both projects, comprising 27 interviews with a range of project stakeholders across both projects. The university is not named for anonymity purposes.

Whilst both projects relate to climate praxis through greenhouse gas reduction in the university's energy systems, the projects' foci differed. 
The first project aimed to demonstrate the safe, efficient and nondisruptive distribution of blended hydrogen in the gas network. The second project focused on the development of a smart energy network management system linked to a significant increase in onsite renewable electricity generation. Both were multi-million-pound projects supported by public funding. The hydrogen project was led by one of the UK's gas distribution network operators, alongside the university and industrial partners. The project utilised the university's private gas network as the first trial stage prior to a public site trial. In contrast, the smart energy network project was led by the university, with a major engineering multinational corporation as the key design and delivery partner. This project aimed to make the campus a research and development facility, creating an at-scale living lab where smart energy strategies and technologies could be researched, developed and tested in a real-world environment, whilst also delivering against ambitious onsite carbon reduction targets.

The university hosting these projects is a semi-rural campus university with a student population of 10,000 and a large campus estate of 600 acres. As well as accommodating over 3,000 students on campus (largely in on-campus halls of residence), there are over 100 properties on campus for staff (and former staff) residents. These properties range from flats to detached houses and have a mix of owner-occupied and rental properties where the university acts as the landlord. A proportion of residences on campus are second homes for staff who have permanent residences at a distance from the university, and only spend a portion of a week or the year living on the campus, whilst other campus residences are permanent homes for staff and their families. An array of catering, leisure and retail amenities also exists. These aspects, alongside its private utility networks, make it a particularly attractive site as a living lab for at-scale climate praxis innovations.

\section{UNDERSTANDING THE EXPERIENCE OF Living IN A LIVING LAB}

Key to the concept of a living lab is that there are 'users' interacting with its technological and governance systems as part of their normal routine. In the context of our case studies, the users range from the staff and student residents and campus users to the estates-based staff with responsibility for the operation and services of the built environment. 
Reflecting on interviews with the living lab residents highlights the diverse views that can exist about being part of such projects. Attitudes towards and prior experiences with the university itself appear to strongly influence residents' perceptions of projects and their willingness to actively engage. Whilst our interviews demonstrated that some residents may feel very positive about the projects and pride in their and the university's involvement, other residents showed some dissatisfaction.

One issue that was raised was how households are recruited to be part of the living lab and the limited opportunity to 'opt out' with some residents believing the university was making proprietary decisions over the residents' private spaces. In a university living lab where many of the 'users' are academics engaging regularly and explicitly with issues of research ethics, sensitivities on the issue of consent may be particularly heightened. This needs careful consideration and management by project implementers particularly if there are longer-term aspirations to include the whole campus environment as a living lab. These issues reflect wider debates about the role of informed consent as an integral element of justice within the transition to a new energy future (Sovacool \& Dworkin, 2015). Whilst these issues are relevant for all living labs, there are important nuances in a university setting due to the complex relationships between project implementers and living lab 'users'.

In addition, privacy concerns for some influenced project implementation. Specifically, some campus households were unhappy about the request for smart meter installation, mirroring privacy concerns in the general population (see, for example, McKenna et al., 2012). We found the desire for privacy potentially compounded by increased sensitivities relating to the complex relationship between resident and university employer, and interestingly heightened in times of university-wide work-related disputes. These reflections underscore the need for project implementers to be sensitive to the ways in which users' perception of a technology is potentially entangled with their social identities and their contexts in complex and dynamic ways (Callon \& Rabeharisoa, 2003), and how this plays out in a university setting.

Whilst residents' prior experiences of, and assumptions about, the university play out in their perceptions of being involved in a university living lab, project implementers' assumptions about, and previous experiences of, residents and other users may also influence how residents and other users are incorporated into and engaged within projects. Our reflections demonstrate that residents often viewed themselves as active 
stakeholders in the projects with an active interest in and expectations of being kept informed about the projects. In contrast, project implementers wanted to reduce disturbing residents by limiting communication when no direct resident input was seen as necessary, leading to dissatisfaction for some residents.

Our reflections on interviews with diverse living lab stakeholders and our own positionalities highlight the need for project implementers to acknowledge the important role of users within a living lab, recognising these as key, often very engaged stakeholders, and hence the need to ensure that their voices are heard. Effectively embedding users at the centre of living labs requires community engagement expertise and necessitates a model of governance adaptable to the needs of users, which are not necessarily automatically part of standard university estate project implementation. Rather than seeing engagement as a single-stage or outcome in the project delivery, a greater focus on user-centred governance can contribute to project success by delivering instrumental benefits (increasing participant engagement and project support), substantive benefits (where greater communication leads to better-informed decisionmaking) and normative benefits (where a 'just' process is developed). Investing time and money into ongoing engagement with user communities should be prioritised at the highest level in the governance of all living lab climate praxis projects.

\section{Maximising Learning and Preparing Society for the Sustainable Energy Transition}

Universities are places of learning. Yet learning takes place not just through the formal curriculum, but through informal learning opportunities, including activities outside the classroom and from the campus environment itself. University living labs therefore may offer the opportunity to capitalise on this learning mission, to enhance climate praxis and energy-literacy learning among all its stakeholders.

Increasing citizens' 'energy literacy', the understanding of energy and its role in society has two important functions. First, it allows informed citizen engagement with energy decision-making, which many authors believe will subsequently increase individual support for investment in a low carbon pathway (DeWaters et al., 2013). Second, it enables decisionmaking over personal energy practices to be informed by energy realities (Hogan et al., 2019; Martins et al., 2020). We are living through an 
energy paradigm shift, characterised by the decarbonisation, decentralisation, digitisation and democratisation of our energy systems (Becker \& Naumann, 2017). However, little of the current transitions towards this shift is visible to the wider public. This 'invisibility' of parts of the energy system could in part explain low levels of energy literacy among citizens (Cotton et al., 2016).

Research on the energy literacy of students has highlighted both the patchy energy knowledge of students and the potential for sustainability and by extension energy learning, from the campus environment (Cotton et al., 2015). A further potential benefit of user engagement around specific campus-based energy projects is the potential to catalyse wider engagement with pro-environmental behaviours, due to increased environmental consciousness-raising. Therefore, university living lab climate praxis projects provide the potential to increase the energy literacy of campus energy users, increase users' energy-transition readiness as well as potentially promote wider pro-environmental behaviours.

Our reflections on the communication and engagement of the climate praxis projects discussed here are that they were largely focused on individuals affected by the projects in their private spaces, with more limited engagement with energy users within the university's public spaces, such as building managers, building users and students using university facilities and in halls of residence. By omitting a deeper level of engagement with these wider, diverse 'public' energy user audiences, potentially important opportunities to enhance wider engagement with energy transitions and climate praxis are missed. To ensure such learning opportunities are not missed, effective wider stakeholder engagement with climate praxis projects is required across the diverse energy users on a university campus, and educational goals need to be embedded in project governance from the start. This seems particularly important for a university living lab within the context of a university's core educational mission and the opportunities to integrate students into living lab activities. However, considering the potential for further learning of all stakeholders in any living lab should also be considered explicitly.

A final area of reflection concerning maximising learning is how university project teams learn from their own practices and experiences, and how the characteristic of flexible, adaptive governance required by living labs is ensured (Evans et al., 2015). Our path to a sustainable future is not predetermined and requires reflexive learning and governance structured around multiple stakeholders and co-creation (McCrory et al., 2020), as 
well as different disciplinary perspectives to maximise learning and test assumptions. Therefore, project teams should adopt the principles of a 'learning organisation' with diverse project stakeholders working together to improve capacities and transform practice (Senge, 2006). Organisational learning could be achieved by embedding research and evaluation of the 'living lab' process and user experience into project governance. However, project teams should go further and develop a genuinely cross-university community of practice (Wenger, 1999), drawing together different areas of expertise to help overcome the barriers to effective jointaction and create more legitimacy for the living lab and the broader goals of sustainability. A community of practice should not be exclusive to those working within the project teams, but should include more interaction with the users and their communities in which living labs are situated to develop a more nuanced understanding of the context for living lab interventions but also to enable greater social learning.

\section{CONCLUSION}

Universities are important spaces as living labs for exploring sustainable solutions due to the mixed-use built environment, private infrastructure and potential to link with the research, education and business engagement missions of the university. However, there is also a need to recognise the complexities, sensitivities, challenges and differences that may be particular to university settings as living labs.

To maximise the potential of universities as living labs for climate praxis requires:

1. Sensitivity to the lived experience of those within the living lab, with careful consideration in climate praxis projects of the role of informed consent in participation, the implications of overlap between the public and private spheres within the university ecosystem and attention to the complex, multifaceted relationships that exist between members of the university community.

2. Effective communication with all project stakeholders and the wider university community, drawing in expertise in community engagement and communication, ensuring sufficient frequency and depth to respect the role of stakeholders as energy users in the living lab, as well as enhance wider learning and energy-transition readiness, and potentially catalyse further pro-environmental behaviour. 
3. Project design and governance that allow reflexive learning of climate praxis within the university and encompass the wider educational and research missions and interdisciplinarity inherent in a university, and that embed mechanisms for learning from user experiences and the 'living lab' process itself.

University living labs can support carbon reduction on the estate itself and share learning to be utilised for other university campuses; they can also provide distinct testbed environments for climate praxis interventions that can be utilised outside of the university environment. However, care needs to be taken to consider the transferability of learning between the university context and wider environment. Although many living lab projects on universities may focus on a core goal of emissions reductions from the estate, universities stand apart as places of learning and research. To maximise the real potential of universities as living labs, the design and governance of climate praxis projects must not just focus on the estate, but the learning to be gained through their education and research missions and the potential to disseminate such learning.

\section{REFERENCES}

Becker, S., \& Naumann, M. (2017). Energy democracy: Mapping the debate on energy alternatives. Geography Compass, 11(8), el2321.

Birch, E., Perry, D. C., \& Taylor, H. L., Jr. (2013). Universities as anchor institutions. Journal of Higher Education Outreach and Engagement, 17(3), $7-15$.

Callon, M., \& Rabeharisoa, V. (2003). Research "in the wild" and the shaping of new social identities. Technology in Society, 25(2), 193-204.

Colding, J., \& Barthel, S. (2017). The role of university campuses in reconnecting humans to the biosphere. Sustainability, 9(12), 2349.

Cotton, D. R. E., Miller, W., Winter, J., Bailey, I., \& Sterling, S. (2015). Developing students' energy literacy in higher education. International Journal of Sustainability in Higher Education, 16(4), 456-473.

Cotton, D., Miller, W., Winter, J., Bailey, I., \& Sterling, S. (2016). Knowledge, agency and collective action as barriers to energy -saving behaviour. Local Environment, 21(7), 883-897.

DeWaters, J., Qaqish, M., Graham, M., \& Powers, S. (2013). Designing an energy literacy questionnaire for middle and high school youth. The Journal of Environmental Education', 44(1), 56-78. 
Evans, J., \& Karvonen, A. (2014). 'Give me a laboratory and I will lower your carbon footprint' Urban laboratories and the governance of lowcarbon futures. International Journal of Urban and Regional Research, 38(2), 413-430.

Evans, J., Jones, R., Karvonen, A., Millard, L., \& Wendler, J. (2015). Living labs and co-production: University campuses as platforms for sustainability science. Current Opinion in Environmental Sustainability, 16, 1-6.

Hogan, S., Pascale, A. Cetois, A., \& Ashworth, P. (2019). Building Australia's Energy Literacy. Prepared for National Energy Resources Australia, The University of Queensland, n.d. https://www.nera.org.au/Featured-energy-lit eracy

Martins, A., Madaleno, M., \& Ferreira Dias, M. (2020). Energy literacy: What is out there to know? Energy Reports, 6(Suppl. 1), 454-459.

McCrory, G., Schäpke, N., Holmén, J., \& Holmberg, J. (2020). Sustainabilityorientated labs in real-world contexts: An exploratory review. Journal of Cleaner Production, 277. https://doi.org/10.1016/j.jclepro.2020.123202

McKenna, E., Richardson, I., \& Thomson, M. (2012). Smart meter data: Balancing consumer privacy concerns with legitimate applications. Energy Policy, 41, 807-814.

Senge, P. M. (2006). The fifth discipline: The art and practice of the learning organization (2nd ed.). Random House.

Sovacool, B. K., \& Dworkin, M. H. (2015). Energy justice: Conceptual insights and practical applications. Applied Energy, 142, 435-444.

Wenger, E. (1999). Communities of practice: Learning, meaning, and identity. Cambridge University Press. 
Open Access This chapter is licensed under the terms of the Creative Commons Attribution 4.0 International License (http://creativecommons.org/licenses/ by $/ 4.0 /$ ), which permits use, sharing, adaptation, distribution and reproduction in any medium or format, as long as you give appropriate credit to the original author(s) and the source, provide a link to the Creative Commons license and indicate if changes were made.

The images or other third party material in this chapter are included in the chapter's Creative Commons license, unless indicated otherwise in a credit line to the material. If material is not included in the chapter's Creative Commons license and your intended use is not permitted by statutory regulation or exceeds the permitted use, you will need to obtain permission directly from the copyright holder.

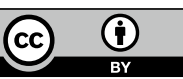

